\title{
The epidemiology and prophylaxis of hepatitis B in sub-Saharan Africa: a view from tropical and subtropical Africa
}

\author{
C F Kiire
}

\begin{abstract}
There are approximately 50 million chronic carriers of hepatitis $B$ virus (HBV) in Africa, with a $25 \%$ mortality risk. In sub-Saharan Africa, carrier rates range from 9-20\%. Many studies have suggested that HBV transmission in Africa occurs predominantly in childhood, by the horizontal rather than the perinatal route. The exact mode of transmission is uncertain but probably involves percutaneous infection through saliva or traces of blood, as well through unsterile needles, tribal scarification, and other possible vehicles. Compared with adult HBsAg carriers in the Far East, those in Africa have a low rate of $\mathrm{HBeAg}$ positivity, which may account for the relatively low rates of perinatal infection. It is also possible that African infants are less susceptible to perinatal $\mathrm{HBV}$ infection compared with their Asian counterparts. Alternatively, it may be that African infants are indeed infected with $\mathrm{HBV}$ at birth but, for genetically determined reasons, have persistently negative tests for a number of years until the virus is reactivated. In view of the high HBV carrier rates in the general population, universal immunisation of all infants is recommended. Ways of incorporating the hepatitis $B$ vaccine into the Expanded Programme on Immunisation in each country are being evaluated.

(Gut 1996; 38 (suppl 2): S5-S12)
\end{abstract}

Keywords: hepatitis B, sub-Saharan Africa, horizontal transmission, immunisation.

By any yardstick, hepatitis B stands out as an important public health problem warranting high priority efforts, prevention, and control. Approximately 300 million people - over 5\% of the world's population - are chronic carriers of the hepatitis B virus (HBV), of whom it is estimated that $25-30 \%$ will die of the sequelae of their infection, principally cirrhosis and hepatocellular carcinoma. ${ }^{1-3}$

In regions of the world where hepatitis $B$ is Mepartment of of Zimbabwe Medical School, Harare, Zimbabwe

C F Kiire

Correspondence to: Dr C F Kiire, Department of Medicine, West Lancashire NHS Trust, Ormskirk \& Nistrict General Hospital, Lancashire L39 2AZ. highly endemic, HBV accounts for around $3 \%$ of the total mortality, ranking with other vaccine preventable childhood diseases such as measles, tetanus, pertussis, and polio. ${ }^{4}$ Of the world's approximately five billion people, $3.8 \%$ live in areas of moderate to high hepatitis $\mathrm{B}$ endemicity (carrier rate $>2 \%$ ). The burden of chronic carriage falls predominantly in Asia where $75 \%$ of chronic HBV carriers live. ${ }^{2}$ Africa has the second largest number of chronic carriers. Of approximately 470 million people living in Africa, about 50 million are lifetime carriers of the virus and as many as 12.5 million will eventually die due to hepatitis $\mathrm{B}$ induced liver disease. This represents a risk of $25 \%$ among chronic carriers.

\section{Epidemiology of HBV in sub-Saharan Africa}

The size and diversity of the African continent, the dispersion of much of its population among vast rural areas, and the frequent lack of resources mean that accurate determination of HBV carrier rates can be extremely difficult. Moreover, assessment of ongoing infectivity and potential precore mutant infection is limited by the lack of polymerase chain reaction testing for HBV-DNA in the great majority of centres. Nevertheless, the epidemiology of HBV infection has been extensively investigated in certain parts of sub-Saharan Africa. ${ }^{5-24}$ Table I shows the prevalence of hepatitis B surface antigen (HBsAg) and other $\mathrm{HBV}$ markers in some of the countries in subSaharan Africa. It is quite clear that the whole of sub-Saharan Africa falls into the high endemicity category (HBsAg carrier rates 9-20\%). Between $56 \%$ and $98 \%$ of the adult population shows evidence of past exposure to and infection with HBV.

The epidemiology of HBV has been studied by various workers in West Africa. In this region, nearly everyone is infected during childhood. ${ }^{67}$ In contrast with the situation in parts of the Far East where a high proportion of the population acquires infection perinatally, $\mathrm{HBV}$ infection of newborns is uncommon in west Africa. However, infection rates increase rapidly

TABLE I Prevalence of $H B s A g$ and $H B V$ markers in the adult population of sub-Saharan Africa

\begin{tabular}{lll}
\hline Country & HBs $\mathrm{Ag}+v e(\%)$ & HBV marker $+v e^{\star}(\%)$ \\
\hline Ethiopia & 11.0 & 79.0 \\
Kenya & 11.4 & 56.2 \\
Mozambique & 14.6 & 75.2 \\
Nigeria & 10.0 & 72.5 \\
South Africa & 9.6 & 76.0 \\
Namibia & 14.0 & 87.5 \\
Zimbabwe & 10.0 & 76.0 \\
Senegal & 11.8 & 91.0 \\
Gambia & 10.0 & 90.0 \\
Zaire & 20.6 & 78.9 \\
Burundi & 11.0 & 76.0 \\
Mali & 11.3 & 97.7 \\
\hline
\end{tabular}

${ }^{\star} \mathrm{HBV}$ marker includes $\mathrm{HBsAg}$, anti-HBc, anti-HBs. 
from the age of 6 months so that, by the age of 2 years, $40 \%$ of west African children have already been infected with HBV and $15 \%$ have developed persistent infection. By the age of 10 years, $90 \%$ of children have become infected and $20 \%$ have become chronic carriers.

The precise mode of transmission of the virus in west Africa is unknown but a number of studies have attempted to look at some of the factors that may be responsible for the apparently high rate of transmission, particularly among young children. A study from Liberia ${ }^{8}$ looked at the prevalence of hepatitis $B$ among children aged up to 4 years. Children born to mothers who were carriers of HBsAg had significantly higher age specific incidence and prevalence of $\mathrm{HBV}$ infection. However, it was estimated that only a minor proportion (less than $5 \%$ ) of hepatitis B infection in Liberia was due to perinatal transmission from mothers.

Another study from Liberia9 attempted to link the high prevalence of HBV infection to parasitic infection (onchocerciasis). In a rubber plantation where onchocerciasis was also common, the HBsAg carrier rate was 30\% compared with a carrier rate of $13 \%$ elsewhere in Liberia where onchocerciasis was rare. The hypothesis was that the high $\mathrm{HBsAg}$ carrier rate in Liberia was linked to the immunosuppression associated with parasitic infections such as onchocerciasis and that this could also explain the high carrier rates found elsewhere in Africa.

An interesting study from The Gambia showed considerably different prevalences of $\mathrm{HBV}$ infection in two neighbouring villages. ${ }^{6}$ Sixty two per cent of children in Manduar village aged 2-4 years were found to be infected, whereas in Keneba, only $27 \%$ of this age group were infected. In both villages, few children below the age of 1 year were infected - none under 6 months of age and only two of 58 between the ages of 6 and 12 months. Eighty six per cent of all children under the age of 5 carried HBsAg, thus forming a highly infectious pool. Infection clustered in families with transmission from sibling to sibling being of major importance. The chances of a child being an HBsAg carrier were approximately $42 \%$ if an elder sibling carried the antigen, $27 \%$ if either the mother or father was a carrier, and $15 \%$ if neither parent was a carrier.

A study from $\mathrm{Mali}^{10}$ showed an $\mathrm{HBsAg}$ prevalence of $8.7 \%$ in 1860 rural Malians and $11.3 \%$ in 764 blood donors. Among 1350 hospitalised patients, no correlation could be established between the HBsAg chronic carrier state and other infectious diseases, malnutrition or genetic deficiencies.

Much of the pioneering work on the epidemiology of hepatitis B was carried out in Senegal. ${ }^{11-13}$ Coursaget et al looked at HBV infection in 155 infants with a view to determining the factors involved in the development of chronic infection. ${ }^{13} \mathrm{~A}$ chronic carrier state was seen in $50.3 \%$ of the infants. The study confirmed that the risk of chronic carriage declined rapidly with increasing age, falling from $82 \%$ in infants under 6 months old to $15 \%$ in children between the ages of 2 and 3 years. A difference was also seen between males and females in that HBV infection before 2 years of age led to a chronic carrier state in $77 \%$ of males compared with $50 \%$ of females.

Studies in central Africa have shown similar findings to those in west Africa. In Zambia, the contribution of horizontal transmission to the high prevalence of $\mathrm{HBV}$ infection was examined. ${ }^{14}$ Six hundred and twenty residents of five Zambian villages were tested for $\mathrm{HBV}$ markers. By comparing paired serum samples from 79 children and 80 adults, it was found that new infections occurred during the five years of this study in at least 14 children $(18 \%)$ and 10 adults $(12 \%)$. These 24 new infections were distributed among 20 households and were consistent with a pattern of horizontal infection.

Baseline epidemiological studies on HBV infection have also been carried out in Southern Africa. In one such study carried out in KaNgwane, a district in South Eastern Transvaal bordering Mozambique and Swaziland, the HBsAg carrier rate was $14.6 \%$ in adult males and $4.6 \%$ in adult females while $82.6 \%$ of adult males and $69 \cdot 4 \%$ of adult females were positive for at least one marker. ${ }^{15}$ When stratified by age, the prevalence varied from $1 \%$ during the first 6 months of life to $11 \cdot 8 \%$ at the ages of $3-5$ years. The group with the highest infectivity, as determined by the prevalence of $\mathrm{HBeAg}$ among $\mathrm{HBsAg}$ positive subjects, were children below the age of 5 years, who had an $\mathrm{HBeAg}$ positivity rate of $56.5 \%$.

Another noteworthy study was carried out in Namibia (previously South West Africa). ${ }^{16}$ The HBsAg carrier rate was found to be $17 \%$ in adult males and $11 \%$ in females. Fifteen per cent of HBsAg carriers - both males and females - were positive for $\mathrm{HBeAg}$. Anti-HBe antibody was present in $66 \%$ of male $\mathrm{HBsAg}$ carriers and $73 \%$ of female $\mathrm{HBsAg}$ carriers. Among children surveyed in this study, only $1 \%$ of those up to 6 months of age were $\mathrm{HBsAg}$ positive compared with $13 \%$ of those over 1 year of age. Only $4 \%$ of $\mathrm{HBsAg}$ positive children were under 6 months old and only $27 \%$ of $\mathrm{HBsAg}$ positive mothers had $\mathrm{HBsAg}$ positive children. The study supported the view that horizontal transmission of $\mathrm{HBV}$ was relatively more important than perinatal transmission in Namibia.

A study of chronic HBV infection among urban black children in Soweto, Johannesburg, South Africa, showed a surprisingly low prevalence of HBV markers with $89 \%$ (2097 of 2364 children) negative for all markers. ${ }^{17} \mathrm{HBsAg}$ was detected in $0.97 \%$ of the children, anti$\mathrm{HBc}$ and anti-HBs together in $6.6 \%$, anti-HBc alone in $0.7 \%$, and anti-HBs alone in 3\%. By contrast, about $15 \%$ of black children from the rural areas of South Africa were found to chronically infected. This remarkable difference in the HBV carrier rate between urban and rural black children in South Africa offers a unique opportunity to investigate the unfavourable influences operating in a rural environment. In rural areas, which are invariably of lower socioeconomic status, there are a 
number of factors that could play a part in the significantly higher HBV infection rates. These include poorer hygiene, with greater chances of HBV transmission through skin abrasions, the use of unsterile needles, tribal scarification, insect bites, and many others. They may also play a part in horizontal transmission of HBV in other areas of sub-Saharan Africa.

In east Africa, most of the studies on hepatitis $B$ have been carried out in Kenya and Ethiopia. In Kenya, a number of seroepidemiological studies show a high prevalence of HBV infection, with $\mathrm{HBsAg}$ carrier rates ranging from 5 to $30 \%{ }^{18-20}$ One early study in a rural community in Kenya, using the counterelectrophoresis method of testing, showed an $\mathrm{HBsAg}$ carrier rate of $5 \cdot 1 \%{ }^{18}$ Antigenaemia occurred first in early childhood, reaching a peak of $10 \cdot 1 \%$ at 14 years and then declining to less than $1 \%$ in those older than 60 years. ${ }^{18}$ One point of particular interest was the finding of a strong intrafamilial spread of HBV. A more recent study has shown no significant perinatal transmission. ${ }^{20}$ Instead, HBV transmission was found to be largely horizontal with the first peak occurring in early school age and a second peak during puberty and childbearing age.

In Ethiopia, the prevalence of HBV markers has also been extensively studied. ${ }^{21-23}$ For instance, among blood donors, the $\mathrm{HBsAg}$ carrier rate was found to be $11 \%$ with a total $\mathrm{HBV}$ infection rate - including antibodies - of $79 \%$. Once more, the predominant form of HBV transmission in Ethiopia was found to be horizontal intrafamilial spread, with factors such as tattooing, tonsillectomy, circumcision, and ear piercing using unsterile instruments possibly playing a part.

In Zimbabwe, our studies have confirmed what has been found elsewhere in sub-Saharan Africa. ${ }^{24}$ Thus, although perinatal transmission of HBV does occur, it is less important than horizontal transmission. Possibly a major reason for the relatively low rate of perinatal transmission is the fact that only $5-15 \%$ of HBsAg positive persons in Zimbabwe are also $\mathrm{HBeAg}$ positive. In Taiwan, in contrast, where perinatal transmission is common, $40 \%$ of $\mathrm{HBsAg}$ positive mothers are $\mathrm{HBeAg}$ positive.

There is evidence that the expression of $\mathrm{HBeAg}$ in different populations may be genetically determined. ${ }^{25}$ It is also possible that it is not only the frequency of $\mathrm{HBeAg}$ positivity in mothers that is genetically determined but also the susceptibility of infants to perinatal infection. In a study in Saudi Arabia, for example, newborns to $\mathrm{HBsAg} / \mathrm{HBeAg}$ positive mothers did not acquire $\mathrm{HBV}$ infection perinatally and remained free of infection when followed up for two years. ${ }^{26}$ In contrast, Chinese babies born to $\mathrm{HBsAg} / \mathrm{HBeAg}$ positive mothers generally acquire $\mathrm{HBV}$ infection in the first 6 weeks to 3 months of life. ${ }^{27}$

The phenomenon of horizontal transmission of HBV has never been adequately explained. It is possible that the so called horizontal infection of HBV in children may not really represent transmission from one child to another. Children may, in fact, be infected with HBV during delivery and remain persistently infected but, for several genetically determined reasons, have no discernible manifestation of infection for many years, using ordinary test procedures. The virus could then be reactivated subsequently. On the other hand, many people believe that true horizontal infection does occur. It is known that the virus replicates in two cell types, the hepatocyte and certain lymphocytes. ${ }^{28}$ Nevertheless, viral antigens, and probably also infectious virus, are present in many body fluids and secretions, notably saliva, ${ }^{29}$ and possibly very small amounts of blood on skin wounds, and these could be vehicles for horizontal transmission, in addition to the other risk factors described earlier. For instance, transmission of $\mathrm{HBV}$ is known to have followed human bites, ${ }^{30}$ suggesting that saliva may be infectious when inoculated percutaneously.

In summary, the vehicle in which $\mathrm{HBV}$ is transmitted horizontally is not clear but it may be saliva or minuscule quantities of blood. The route of infection is probably percutaneous, through skin abrasions, skin lesions (such as impetigo or eczema), and skin bites, which are not uncommon, particularly among children, in the rural areas of sub-Saharan Africa. However, covert perinatal transmission, with HBV infection manifesting later, cannot be discounted.

\section{Hepatitis $B$ vaccination studies in sub-Saharan Africa}

A number of vaccination studies have been carried out in sub-Saharan Africa. The initial studies confirmed the immunogenicity of hepatitis $B$ vaccines in African neonates. ${ }^{30} 31$ In Senegal, an inactivated plasma derived vaccine (HevacB, Pasteur Institute) was given to 26 infants aged less than 1 month; $95 \%$ of the neonates showed a specific antibody response to HBsAg, similar to those in older children. ${ }^{30}$ The vaccine was used in a schedule of three injections at monthly intervals and was without side effects. Immune responses were impaired by maternal anti-HBs. In another study, carried out in KaNgwane, South Africa, three groups of babies were included: newborns, and those aged 3 months and 6 months. ${ }^{31}$ A recombinant vaccine (H-B-Vax, Merck, Sharpe and Dohme) was used in three doses of $10 \mu \mathrm{g}$, given at intervals of zero, one, and five months. Ninety three per cent of the babies in each age group seroconverted to anti-HBs, clearly establishing the immunogenicity of the vaccine in young babies. In this study, the presence of maternal anti-HBs in the baby's serum did not interfere with immunisation.

Subsequent studies, mainly in Senegal, looked at various aspects of hepatitis B immunisation in an endemic area. One such study looked at hepatitis $B$ vaccination in children with previously acquired hepatitis $B$ surface antigenaemia. ${ }^{32}$ Three doses of HevacB were given at one month intervals to 31 Senegalese children aged 3 to 24 months who were positive for HBsAg. A control group of $18 \mathrm{HBsAg}$ positive Senegalese children received diphtheria-tetanus-polio (DTP) vaccine. Immunisation of HBsAg positive infants 
with hepatitis B vaccine was safe but ineffective. After a 12 month follow up, the prevalence of chronic carriers of HBsAg was not significantly reduced in the hepatitis $B$ vaccine group compared with the control group (48.4 and $66 \cdot 7 \%$, respectively).

Another study looked at hepatitis B immunisation in pregnancy. ${ }^{33} \mathrm{HevacB}$ was given to pregnant Senegalese women to improve passive protection of their children. The vaccine was without side effects in mothers and their newborns. After three injections of hepatitis B vaccine, $77 \cdot 4 \%$ of the mothers were found to have anti-HBs compared with $44.5 \%$ of nonimmunised mothers. The vaccination did not significantly reduce the number of $\mathrm{HBsAg}$ carrier mothers but it ensured the transmission of passive anti-HBs antibodies to $60 \%$ of the newborn babies as against $32 \%$ in children born to non-immunised mothers. However, such protection was of short duration and difficult to apply in rural areas of tropical Africa. Moreover, no protection was provided to those children born to $\mathrm{HBeAg}$ positive mothers, who represent a potential risk factor for infection of their babies.

Several studies have evaluated the simultaneous administration of hepatitis $B$ vaccine and other vaccines. In one such study, the interaction of hepatitis B and DTP vaccine was investigated in Senegal. ${ }^{34}$ The immune response was evaluated when the vaccines were given either together or separately to children. The immune response to $\mathrm{HBsAg}$ vaccine and DTP vaccine injected simultaneously was equal to the immune response seen after each of these vaccines was given alone. Moreover, no adverse reactions were noted.

Simultaneous administration of hepatitis B and yellow fever vaccines was also studied in Senegalese children. ${ }^{35}$ Yellow fever antibodies were detected in a similar proportion of infants immunised with yellow fever vaccine alone or associated with hepatitis B vaccine. However, yellow fever antibody values were slightly lower when both vaccines were given at the same time. Nevertheless, it was felt that the difference in antibody titres between infants receiving yellow fever vaccine alone or associated with hepatitis B vaccine had no implication for the yellow fever programme of immunisation in west Africa, as it is the practice to give booster doses to the general population when new cases of yellow fever appear.

A number of studies also looked at simpler and cheaper ways of hepatitis $B$ vaccine administration, as most developing countries have problems with regard to infrastructure, manpower, and the cost of the vaccine, which, until recently, has been quite expensive. In one such study, using HevacB 350, Senegalese infants aged 3-5 months were randomly allocated to three groups: group A (two doses of $5 \mu \mathrm{g}$ two months apart), group B (two doses of $2 \mu \mathrm{g}$ two months apart), and group C (three doses of $2 \mu \mathrm{g}$ one month apart). All had a booster ( 5 or $2 \mu \mathrm{g}$ ) six months after the first dose. ${ }^{36}$ In group $\mathrm{A}$, the seroconversion rate was $96 \%$ after the booster dose and the geometric mean titre (GMT) was $848 \mathrm{mIU} / \mathrm{ml}$. The two doses of $2 \mu \mathrm{g}$ (group B) provided an unsatisfactory seroconversion rate and GMT. However, the results in group $C$ (three doses of $2 \mu \mathrm{g}$ ) were very good with a GMT after the booster dose of $1660 \mathrm{mIU} / \mathrm{ml}$ and $95 \%$ protection at six months. Thus, either three doses of $2 \mu \mathrm{g}$ hepatitis B vaccine with a booster at six months or two doses of $5 \mu \mathrm{g}$ plus a booster at six months were recommended as being effective and economical.

Another study from Senegal compared the immunogenic effect of hepatitis $B$ vaccine (HevacB) in children using a two and three dose protocol. ${ }^{37}$ Seventy two seronegative infants received two doses of $5 \mu \mathrm{g}$ at a two month interval and 111 infants received three doses of $5 \mu \mathrm{g}$ at one month intervals. All children had a booster at one year. No difference was seen between the two groups in the seroconversion rate $(93.1$ and $94.6 \%$, respectively) or GMT ( 82 and $92 \mathrm{mIU} / \mathrm{ml}$ respectively). The study showed that two doses of $5 \mu \mathrm{g}$ hepatitis B vaccine, with a booster at one year, was sufficient in infants to obtain a high immunogenic effect.

In Nigeria, Ayoola et al looked at the efficacy and immunogenicity of hepatitis B vaccine (HevacB) given intradermally to 125 people (aged 1-45 years) who were negative for HBV markers. ${ }^{38}$ The subjects were randomised into two groups: group 1 comprised 64 volunteers who were given three doses of 2 $\mu \mathrm{g}$ vaccine mixed with adjuvant, given subcutaneously at monthly intervals; group 2 consisted of 61 volunteers who received three doses of $2 \mu \mathrm{g}$ vaccine without adjuvant, given intradermally at monthly intervals. One month after the third dose, $83 \%$ of group 1 and $71 \%$ of group 2 showed a positive anti-HBs response. The levels of antibody were significantly higher in group 1 at each stage of the follow up period, including one month after a booster vaccination was given. The positive response was maintained in almost all the initial responders for the 24 month duration of the study. No significant side effects were reported in any of the participants. The study raised the possibility of protecting the population at risk in developing countries with small doses of vaccine given intradermally. Given the significantly lower anti-HBs antibody titres in group 2 and the difficulties associated with intradermal vaccination on a large scale, however, intradermal hepatitis $B$ vaccination is probably not a viable option for Africa as a whole.

Several studies have provided some insight into the longterm efficacy of hepatitis B vaccine in infants in an endemic area. Coursaget et al, in Senegal, looked at the efficacy of HevacB during a three year follow up after the booster dose in 83 infants. ${ }^{39}$ These infants, who had previously received three injections of $5 \mu \mathrm{g}$ at one month intervals plus a booster dose 12 months after the first injection, were compared with 117 infants from a control group vaccinated only with DTP vaccine. In the vaccine group, the HBV infection rate per year was $0.9 \%$, compared with $14.5 \%$ in the control group. The protective efficacy rate was 
93.8\% if all $\mathrm{HBV}$ events were considered (HBsAg and anti-HBc positive) and $100 \%$ if only HBsAg events were considered. The protective effect was reflected in the levels of antiHBs antibodies in the vaccinated infants from blood samples taken three years after the booster; $97 \cdot 5 \%$ had anti-HBs antibodies and the median anti-HBs titre was $200 \mathrm{mIU} / \mathrm{ml}$.

Yvonnet et al reported the longterm persistence of anti-HBs antibody in 156 Senegalese children vaccinated using the schedule of zero, one, and two months with a booster at 12 months. ${ }^{40}$ Six years after the booster dose, $90.4 \%$ of the children had detectable anti-HBs antibodies, with $78 \cdot 1 \%$ having titres higher than $10 \mathrm{mIU} / \mathrm{ml}$. The GMT was $60 \mathrm{mIU} / \mathrm{ml}$. Females showed higher anti-HBs values than males. In a group of children who received no booster dose, anti-HBs antibodies were detectable seven years after the first dose. However, the GMT was lower $(26 \mathrm{mIU} / \mathrm{ml})$. Revaccination with a booster dose ( 56 children) led to an increase in the GMT to $469 \mathrm{mIU} / \mathrm{ml}$ two months later. The results show that a booster dose at five to six year intervals may be necessary to provide adequate anti-HBs levels.

Another study by the same group followed up the incidence of hepatitis B in 135 children vaccinated against hepatitis $B$ and 143 children constituting the control group (vaccinated with DTP vaccine). ${ }^{41}$ Over the following six years, the incidence of hepatitis B was $1.5 \%$ per year in the group vaccinated against hepatitis B, compared with $11.5 \%$ per year in the control group. In the first four years, the protective efficacy of the vaccine was $100 \%$ but during the fifth and sixth years it fell to $67 \%$. For maximum protection, another booster dose was recommended five years after the first booster.

Perhaps the best known study is the Gambia Hepatitis Intervention Study (GHIS). ${ }^{42}$ This longterm intervention study was designed to evaluate the effectiveness of hepatitis $B$ vaccination for the prevention of chronic liver disease and hepatocellular carcinoma. The study is a joint venture between the Gambian government, The International Agency for Research on Cancer (IARC), and the Medical Research Council (MRC) laboratories in The Gambia and is financially supported by the Department of Co-operation and Development of the Ministry of Foreign Affairs in Italy. The study comprises three overlapping phases:

Phase I: vaccination programme - five years.

Phase II: longitudinal and cross sectional studies of HBV events in selected groups - 10 years.

Phase III: longterm follow up to monitor incidence and prevalence of $\mathrm{HBV}$ related chronic liver disease -40 years.

The study, which started in 1986 , has successfully integrated hepatitis $B$ into the Gambian Expanded Programme on Immunisation (EPI). In 96\% of infants, hepatitis B immunisation elicited adequate protective antibody levels, with the number of nonresponders being $4 \%$ after a three year period of the programme. Serological results from a sample of vaccinated children showed that vaccination was effective in reducing the numbers of persistently infected children. There were no major logistical difficulties and total national childhood immunisation coverage was achieved over a period of four years.

The International Task Force on Hepatitis B Immunisation has recommended the establishment of model immunisation programmes within specific regions before expansion nationwide. ${ }^{43}$ In these model programmes, innovative approaches for incorporating hepatitis $B$ vaccination into the EPI can be evaluated, vaccinators can be retrained, and new educational and motivational material developed. Such model immunisation programmes were initially introduced in Kenya and Cameroon. Since then, other countries in sub-Saharan Africa, such as Botswana, Zimbabwe, Mauritius, and South Africa, have introduced universal infant hepatitis B immunisation programmes as part of their national EPI programmes.

\section{Controlling hepatitis B in sub-Saharan Africa}

The high incidence of $\mathrm{HBV}$ related liver disease, including hepatocellular carcinoma, has made the eradication of HBV one of the most important tasks facing public health authorities in Africa. Although the importance of measures such as blood bank screening for HBV should not be overlooked, immunisation is the single most important factor in any national hepatitis $B$ control programme and has the potential to eradicate hepatitis $B$ and reduce the incidence of chronic liver disease and cancer in Africa. In view of the epidemiology of hepatitis B in sub-Saharan Africa, the concept of high risk groups such as health care personnel, dialysis patients, homosexuals, etc, is irrelevant to immunoprophylaxis. All children should be regarded as being at high risk as most infections are acquired in early childhood.

There are two basic approaches to vaccination programmes in sub-Saharan Africa: mass vaccination of all infants (without screening for HBsAg) and immunisation only of infants born to HBsAg positive mothers. As horizontal, not perinatal, transmission seems to predominate, the second approach can only reduce the $\mathrm{HBV}$ chronic carrier rate by a small percentage, while the limited resources available in the region means that large scale testing of pregnant women is not feasible. Therefore, mass vaccination of all infants would be the most effective approach to hepatitis $B$ prevention and control in sub-Saharan Africa.

The target population for hepatitis $B$ vaccination in Africa is enormous. However, in the absence of a childhood vaccination programme, one would expect millions to die from hepatitis $B$ related diseases in adulthood. In Mozambique, for example, the age standardised incidence rate for hepatocellular carcinoma in males is 103.8 per 100000 per year. ${ }^{44}$ It accounts for no less than two thirds of tumours in men and one third of those in women.

The incorporation of hepatitis $B$ vaccine into the EPI is the most cost effective strategy 
TABLE II Options for adding hepatitis $B$ vaccination to the Expanded Programme on Immunisation schedule recommended by the World Health Organisation

\begin{tabular}{llllll}
\hline & $\begin{array}{l}\text { Contact } \\
\text { Age }\end{array}$ & Option & & & \\
\cline { 3 - 6 } & number & $I$ & II & III & IV \\
\hline Birth & 1 & BCG, HBV 1 & HBV 1 & HBV 1 & HBV 1 \\
6 weeks & 2 & OPV 1, DTP, HBV 2 & HBV 2 & HBV 2 & HBV 2 \\
10 weeks & 3 & OPV 2, DTP 2 & & HBV 3 \\
14 weeks & 4 & OPV 3, DTP 3 & HBV 3 & HBV 3 & \\
24-48 weeks & 5 & Measles, HBV 3 & HBV &
\end{tabular}

OPV: oral polio vaccine; DTP: diphtheria, tetanus, and pertussis.

for the prevention of hepatitis $B$ infection in sub-Saharan Africa. The use of the hepatitis B immune globulin (HBIg) as an adjunct to vaccination has been advocated in some areas such as the Far East where perinatal transmission is common. The efficacy of hepatitis B vaccine alone is between 75 and $90 \%$, while the efficacy when HBIg is added to hepatitis B vaccination is as high as $95 \%$. The use of $\mathrm{HBIg}$ adds considerable cost to the treatment, however, and is practicable only in countries that can establish and pay for routine resting of pregnant women. It is more cost effective to devote available resources to routine infant immunisation with vaccine alone, and most developing countries will elect to forego use of HBIg.

The schedule of administration of hepatitis $B$ vaccine should be coordinated with the delivery of the other EPI vaccines. Ideally, the first dose of hepatitis $B$ vaccine should be given as soon as possible after birth and, in all cases, at the first immunisation contact. The second dose should be given at the next immunisation contact, and the third dose with the third, fourth or fifth contact. The reason for this variation in scheduling of the third dose of hepatitis $B$ vaccine is that, the longer the interval between the second and third doses, the higher the maximal protective antibody titre achieved. While the achievement of such maximal titres may be theoretically desirable, it is not clear whether such levels have any impact on the duration of protective immunity. The decision to delay the third dose until the time of measles immunisation must be weighed against the possibility that a third dose will not be delivered at all because of lower overall measles immunisation coverage rates.

Table II shows four options for adding hepatitis B vaccine to the recommended EPI schedule. Options I and II emphasise the initial delivery of hepatitis B vaccine at birth and are the recommended options where vaccination at birth is possible. These are particularly relevant to Asia, where perinatal transmission of hepatitis B is common. Options III and IV are for areas where immunisation at birth is not easily accomplished. They might also be more appropriate in regions such as sub-Saharan Africa where perinatal transmission is uncommon. Option IV permits simultaneous delivery with DPT and anticipates the future availability of a combined DPT-hepatitis B vaccine.

As previously mentioned, a number of hepatitis $B$ vaccination programmes have been initiated in sub-Saharan Africa. Perhaps the best known programme is the GHIS, which is the first programme to achieve national coverage in this region. Other important programmes in Kenya and Cameroon, supported by the International Task Force on Hepatitis B Immunisation, have produced a catalytic effect on the launching of hepatitis $\mathrm{B}$ immunisation programmes throughout Africa.

A great deal has been learned from the existing hepatitis $B$ vaccination programmes. For the vaccine to be successfully incorporated into the EPI, comprehensive training programmes for health staff are absolutely essential. Health staff need updated information that a safe, effective vaccine now exists at an affordable price for public sector programmes. They also need to know that hepatitis B vaccine can safely be delivered with the other EPI vaccines and that it has very minor side effects. The administrators and the general public also need to know about the disease, its consequences, and its prevention, including hepatitis B vaccination. They need to know that the vaccine is safe, and that three doses are required for full protection. They also need to be kept informed as to the schedule of hepatitis $B$ vaccination.

Vaccines are currently available on the international market from Merck, Sharpe and Dohme, SmithKline Beecham Biologicals, the Korea Green Cross Corporation, and Cheil Food and Chemicals. Hepatitis B vaccines are also produced in China, Cuba, and Japan but are not yet available on the international market. Plasma derived hepatitis $B$ vaccine has been procured for large scale public sector infant immunisation programmes for as little as $\$ 0.55$ per dose and rDNA-hepatitis $B$ vaccine for as little as $\$ 0.95$ per dose. These are the kind of prices that can be achieved with a large order on an international rather than a local tender and bid. The International Task Force on Hepatitis B Immunisation has expressed its willingness to undertake this task on behalf of several African nations and it is hoped that more countries in sub-Saharan Africa will be willing to participate.

In conclusion, mass hepatitis $B$ vaccination programmes, such as the one in Gambia and the model programmes in Cameroon and Kenya, should be initiated in the rest of subSaharan Africa. Thanks to the efforts of the WHO and the International Task Force on Hepatitis B Immunisation, the dramatic reduction in the price of hepatitis $B$ vaccines now makes this feasible, and the number of countries in sub-Saharan Africa introducing national hepatitis B immunisation programmes continues to grow.

1 WHO Technical Advisory Group on Viral Hepatitis. Progress in the control of viral hepatitis: memorandum from a WHO Meeting. Bull World Health Organ 1988; 4: 443-55.

2 Maynard JE, Kane MA, Alter HJ, Hadler SC. Control of hepatitis $\mathrm{B}$ by immunization: global perspectives. In: Zuckerman AJ, ed. Viral hepatitis and liver diseases. New Zuckerman AJ, ed. Viral hepatins

3 Mork. Alan Riss, haynard JE, Kane MA, Hadler SC. Global control of hepatitis $B$ through immunization: role of hepatitis $B$ vaccine in the Expanded Programme on

4 World Health Organisation. Prevention of liver cancer. Report of a WHO Meeting. WHO Tech Rep Ser 1983; 691: 8-9.

5 Kiire $\mathrm{CF}$ and the African Regional Study Group. Hepatitis $B$ in sub-Saharan Africa. In: Blumberg BS, Hepburn A, 
Andre FE, eds. Proceedings of International Conference on Prospects for Eradication of the Hepatitis B Virus. Vaccine 1990; 8 (suppl): 107-12.

6 Whittle HC, Bradley AK, McLaughlan K, et al. Hepatitis B in two Gambian villages. Lancet 1983; i: 1203-6.

7 Hall AJ, Inskip HM, Loik F, et al. The Gambian Hepatitis $B$ Intervention Study. International Agency for Research on Cancer. Annual Report, 1988: 1-152.

8 Prince AM, White T, Pollock N, Riddle J, Brotman B, Richardson L. Epidemiology of hepatitis $B$ infection in Liberian infants. Infect Immunol 1981; 32: 675-80.

9 Neppert J, Gerlich W. Studies on the serological manifestation of the hepatitis B virus in the Republic of Liberia (author's translation). Zentralbl Bakteriol 1979; 245: 8-16.

10 Maupas P, Chiron JP, Goudeau A, et al. Epidemiology and pathologic results of chronic carrier state of hepatitis B in Mali. Bull Soc Pathol Exot Filiates 1981; 74: 722-32.

11 Szmuness W, Prince AM, Diebolt G, et al. The epidemiology of hepatitis B infection in Africa: results of a pilot survey in the Republic of Senegal. Am F Epidemiol 1973; 98: 843-9.

12 Barin F, Perrin J, Chotard J, et al. Cross-sectional longitudinal epidemiology of hepatitis B in Senegal. Prog Med Viro 1981; 27: 148-67.

13 Coursaget P, Yvonnet B, Chotard J, et al. Age and sexrelated study of hepatitis $B$ in infants from an endemic area (Senegal). $f$ Med Virol 1987; 22: 1-5.

14 Tabor E, Bayley AC, Cairns L, Gerety RL. Horizontal transmission of hepatitis $B$ virus among children and adults in five rural villages in Zambia. $\mathcal{F}$ Med Virol 1985; 15: $113-20$.

15 Prozesky OW, Szmuness W, Stevens CE, et al. Baseline epidemiological studies for a hepatitis B vaccine trial in KaNgwane. S Afr Med f 1983; 64: 891-3.

16 Botha JF, Ritchie MJ, Dusheiko GM, Mouton HWK, Kew MC. Hepatitis B virus carrier state in black children in Ovamboland: role of perinatal and horizontal infection. Lancet 1984; i: $1210-2$.

17 DiBisceglie AM, Kew MC, Dusheiko GM, et al. Prevalence of hepatitis B virus among black children in Soweto. BMY 1986; 292: 1440-2.

18 Baghshawe A, Nganda TN. Hepatitis B antigen in a rural community in Kenya. Trans $R$ Soc Trop Med Hyg 1973; 67: $663-7$.

19 Bowry TR. The pattern of transmission of hepatitis B in an urban population of Kenya. $\mathcal{F}$ Med Virol 1984; 64: 385-91.

20 Hyams KC, Okoth FC, Tukei PM, et al. Epidemiology of hepatitis B in Eastern Kenya. $\mathcal{F}$ Med Virol 1989; 28 : 106-9.

21 Tsega E, Mengesha B, Nordenfelt E, Hansson B, Lindberg J. Prevalence of hepatitis $B$ virus markers among Ethiopian blood donors: Is HBsAg necessary? Trop Geogr Med 1987; 39: 336-40.

22 Tsega E, Mengesha B, Hansson B, Lindberg J, Nordenfelt E. Hepatitis A, B and delta infection in Ethiopia: A serologic survey with demographic data. Am $\mathcal{F}$ Epidemiol 1986; logic survey with

23 Tsega E, Tsega M, Mengesha B, Nordenfelt E, Hansson B, Lindberg J. Transmission of hepatitis B virus infection in Ethiopia with emphasis on the importance of vertical transmission. Int $\mathcal{f}$ Epidemiol 1988; 17: 874-9.

24 Kiire CF. Hepatitis B virus carrier state among black children in Zimbabwe. MD Thesis. Kampala, Makerere University, 1990: 1-90.

25 Ghendon Y. Perinatal transmission of hepatitis B in high incidence countries. $\mathcal{F}$ Virol Methods 1987; 17: 67-79.

26 Basalamah AH, Serebour F, Kazim E. Materno-foetal transmission of hepatitis B in Saudi Arabia. F Infect 1984; 8: $200-4$.

27 Beasley RP, Hwang LY, Stevens CE, et al. Efficacy of hepatitis B immunoglobulin for prevention of perinatal transmission of the HBV carrier state. Final report of a randomised double blind placebo-controlled trial. Hepatology 1983; 3: 135-41.

28 Korba BE, Well F, Tennant BC, Yoakum GH, Purell RH Gerin JL. Hepadnavirus infection of peripheral blood lymphocytes in vivo: woodchuck and chimpanzee models of viral hepatitis. $\mathcal{F}$ Virol $1986 ; 58: 1-8$.

29 Barin F, Goudeau A, Denis F, et al. Immune response in neonates to hepatitis B vaccine. Lancet 1982; i: 251-3.

30 Cancio-Bello TP, de Medina M, Shorey J, Valledor MD, Schiff ER. An institutional outbreak of hepatitis B related Schiff ER. An institutional outbreak of hepatitis B related
to a human biting carrier. F Infect Dis 1982; 146: 652-6. to a human biting carrier. $\mathcal{F}$ Infect Dis 1982; 146: 652-6.
1 Prozesky OW, Stevens CE, Szmuness W, et al. Immune response to hepatitis B vaccine in newborns. F Infect 1983; 7 (suppl 1): 53.

32 Barin F, Yvonnet B, Goudeau A, et al. Hepatitis B vaccine: further studies in children with previously acquired hepatitis B surface antigenemia. Infect Immunity 1983; 41: 83-7.

33 Coursaget P, Chiron JP, Yvonnet B, et al. Hepatitis B immunization in pregnancy: maternal immune response and transmission of anti-HBs antibodies to infants. Int $\mathcal{F}$ Microbiol 1983; 1: 27-34.

34 Coursaget P, Chiron JP, Yvonnet B, et al. Simultaneous administration of hepatitis $\mathbf{B}$ and diphtheria/tetanus/polio administration of hepatitis $B$ and

35 Yvonnet B, Coursaget P, Deubel V, Diop Mar I, Digoutte JP, Chiron JP. Simultaneous administration of hepatitis B yellow fever vaccines. 19th IABS Congress on Use and Standardization of Combined Vaccine. Dev Biol Standard 1985; 65: 205-7.

36 Yvonnet $\mathrm{B}$, Coursaget $\mathrm{P}$, Leboullex $\mathrm{D}$, et al. Low dose hepatitis B immunization in children. Lancet 1987; i: 169.
37 Yvonnet B, Coursaget P, Petat E, et al. Immunologic effect of hepatitis B vaccine in children: comparison of two or three dose protocol. F Med Virol 1984; 14: 137-49.

38 Ayoola EA, Atoba MA, Johnson CA. Intradermal vaccination against hepatitis B infection in an endemic area tion against hepatitis B infection in an endemic area
(Nigeria), two year results. Arch Virol 1986; 91: 291-6. 39 Coursaget P, Yvonnet B, Chiron JP, Diop Mar I. Long term efficacy of hepatitis $B$ vaccine in infants from an endemic area. Ann Virol 1986; 137E: 221-4.

40 Yvonnet B, Coursaget $\mathrm{P}$, Chotard J, et al. Hepatitis B vaccine in infants from an endemic area: long term anti-HBs persistence and revaccination. $\mathcal{f}$ Med Virol 1987; 22: 315-21.

41 Coursaget P, Yvonnet B, Chotard J, et al. Seven year study of hepatitis B efficacy in infants from an endemic area. Lancet 1986; i: 1143-5.

42 Hall AJ, Inskip HM, Loik FM, et al. The Gambia Hepatitis Intervention Study. Annual Report. The International Agency for Research on Cancer, Lyon, 1989: 12-4.

43 The International Task Force on Hepatitis $B$ Immunization. Notes on hepatitis $\mathbf{B}$ and its control. Program for Appropriate Technology in Health (PATH), Seattle, 1988: 1-6.

44 Waterhouse J, Muir C, Powell J, eds. Cancer incidence in five continents. Lyon: WHO, 1977: 122-3.

\section{Discussion}

Zuckerman: What is the rate of loss of $\mathrm{HBeAg}$ in Zimbabwe?

Kiire: We have not looked at this in a prospective manner, but we know that the $\mathrm{HBeAg}$ positivity rate up to the age of 5 years is about $50 \%$, and that only about $10-15 \%$ of mothers are $\mathrm{HBeAg}$ positive. Extrapolating from those figures, we could work out a rate of loss. I think it is much higher than that seen in the Far East.

Zuckerman: Are there any data from South Africa on the rate of loss of $\mathrm{HBeAg}$ or seroconversion to anti-HBe over a period of time? Kew: The $\mathrm{HBeAg}$ positivity rate starts off very high and then falls rapidly. In fact, in South Africa, only $5 \%$ of adult black male carriers are $\mathrm{HBeAg}$ positive.

Goudeau: It is the same in Senegal. The $\mathrm{HBeAg}$ positivity rate starts at $50-60 \%$ before the age of 5 but then declines very rapidly much more rapidly than it does in the Far East. We don't know why.

Hollinger: In clinical trials in the US among immunocompetent adults, in which untreated control groups are used, the frequency for spontaneous loss of $\mathrm{HBeAg}$ is in the range of $5-15 \%$ per year.

Zuckerman: Why do people seroconvert so quickly without any treatment? Is it age related? Kew: In South Africa, we wondered whether we might be seeing conversion to precore mutant infection on a massive scale, but we have recently confirmed that is not the answer. Precore mutants are very rare in black South Africans.

Kiire: The same is true for sub-Saharan Africa. Kew: An interesting piece of information in this regard is that the Chinese who have immigrated to South Africa from China and Taiwan have retained their Eastern pattern. That is, $40 \%$ of Chinese women living in Johannesburg are $\mathrm{HBeAg}$ positive during their reproductive period despite two or three generations in the new environment. This suggests that it is genetically rather than environmentally determined.

Yao: It is interesting that 10 years ago the adult $\mathrm{HBeAg}$ positivity rate in southern China was $50 \%$ but this has fallen very rapidly in recent years, to just $30 \%$. 
Gordeau: What we need to do is follow up African children that have become infected very early in life - like Chinese children - to see whether very early transmission has a part to play in the persistence of $\mathrm{HBeAg}$.

Zuckerman: Another factor that comes into play is the reliability of the serological tests for $\mathrm{HBeAg}$ and anti-HBc.

Goudeau: At least in Europe, we have a problem with testing for anti-HBc. Most of the anti-HBc tests have been prepared for blood transfusion programmes and have therefore been designed to have increased sensitivity to avoid any transmission of hepatitis $B$. Unfortunately, this means that there are now a lot of false-positive reactions because the assays have poor specificity.

Hollinger: Dr Kiire, you said that after four doses of hepatitis $B$ vaccine given at zero, six, 10 , and 14 weeks, only $64 \%$ had made antibodies at one year. After three doses, only 32\% responded. These figures are really low.

Kiire: This is a field situation. We estimated that we would get about a $75 \%$ response rate after four doses, but in fact it was only $64 \%$. Zuckerman: In the UK, we have found many non-responders even among HIV negative subjects. That is, between $10 \%$ and $15 \%$ of adults do not respond to the current vaccines. Another very important point is the antibody level that we consider to represent a response to the vaccine. In the UK, we now have legislation that all medical students and hospital personnel have to be immunised against hepatitis B, but what antibody level should we consider to be protective? Should we take $10 \mathrm{IU} / 1$ or 100 IU/1 as the cut off point?

Hollinger: There seem to be fairly good data that if anti-HBs levels reach at least $10 \mathrm{IU} / \mathrm{l}$, the probability of infection after exposure is very low. Furthermore, if antibody titres reach 100 or $200 \mathrm{IU} / 1$ and then fall to less than 10 $\mathrm{IU} /$, that is not the same as never reaching 10 IU/1 in the first place. The first group will certainly retain their immunity, while the second group remains at risk.

Goudeau: The key point is not really the antibody titre. With an anti-HBs level of $100 \mathrm{IU} / \mathrm{h}$, infection will not occur. But as long as a person has some antibody response - even a very low one - they may become infected but they will not become a chronic carrier, which is most important.

Kiire: Another point is that, in an endemic situation, the recommendation may be slightly different from that where contact with a hepatitis B carrier is unlikely. In the Gambian study, even children with very low antibody titres mounted a fairly good anamnestic response when they were exposed to infection, and anyway were unlikely to become chronic carriers.

Hollinger: In reviewing data on durability of immunity, it is important to recognise that results have been obtained from immunisation with the plasma derived vaccine. This seems to be a stronger immunogen than the recombinant vaccine, perhaps because it has some pre-S material in it and also because of its conformation.

Goudeau: To achieve the same immunisation pattern, you need $20 \mu \mathrm{g}$ of the recombinant vaccine and only $5 \mu \mathrm{g}$ of the plasma derived one.

Hollinger: We probably need to wait a little longer to see whether the recombinant vaccines are less immunogenic or whether it has to do with the way in which they given. We just don't know what the longterm durability is likely to be with either the plasma derived or the recombinant vaccines, especially the latter.

Zuckerman: Would you recommend a booster dose if someone's antibody titre declines to below $100 \mathrm{IU} / 1$ and that person is at risk of exposure to $\mathrm{HBV}$ - a surgeon, for example? Gust: Under those circumstances, boosting is usually recommended, because you know it will do no harm and it may possibly be of benefit. There is, however, no strong scientific basis for that position.

Toukan: Rather than talking about durability of antibody response, perhaps we should be investigating the durability of the immune response in an individual?

Lansang: In the Philippines a few years ago, we tested a single dose of $1.5 \mu \mathrm{g}$ vaccine against three doses. After three years, we retested these children and many of them no longer had detectable antibody. When we gave them a second dose, $69.7 \%$ showed anti-HBs, suggesting that memory cells are still there.

Ahn: What is the seroconversion rate from HBsAg positive to HBsAg negative in Africa? Goudeau: In Senegal, the carrier rate among young adults is about $15 \%$. About half of these will lose HBsAg over three or four years, but they may still eventually die from hepatitis B related cirrhosis or hepatocellular carcinoma even though the virus itself has disappeared. 